\title{
Proceeding
}

Supplementary Issue: Summer Conferences of Sports Science. Costa Blanca Sports Science Events, 25-26 September 2020. Alicante, Spain.

\section{Modern studies of training modalities in the professional sport field}

\author{
WALEED ABDUL-AMEER ALMANI \\ College of Arts, Waist University, Iraq
}

\begin{abstract}
This paper highlights on the different modern trainings at the professional sport activities. All the modern methods of Karate trainings were discussed in details, even the training obstacles that confront coaches. All the modern training methods have seen in details taken from scientific and practical studies belong to the trainee and coaches of that sport. This paper contains more than twenty training method with schedules supported with statistics and comparisons between the basic training methods that are taken from some exercise of different sports such as pushing the iron ball and the hammer's sight, and the influence of these sports to develop the coach and the trainee of karate.
\end{abstract}

Keywords: Karate; Highly intensive; Interval training; Repetition.

\section{Cite this article as:}

Almani, W.A-A. (2020). Modern studies of training modalities in the professional sport field. Journal of Human Sport and Exercise, 15(4proc), S1046-S1058. doi:https://doi.org/10.14198/ihse.2020.15.Proc4.07

Corresponding author. College of Arts, Waist University, Iraq.

E-mail: dr.ghafarsaeedissa@gmail.com

Abstract submitted to: Spring Conferences of Sports Science. Costa Blanca Sports Science Events, 19-20 June 2020. Alicante, Spain.

JOURNAL OF HUMAN SPORT \& EXERCISE ISSN 1988-5202

(c) Faculty of Education. University of Alicante

doi:10.14198/jhse.2020.15.Proc4.07 


\section{INTRODUCTION}

The training modality is different from one to another, and the coach tries to use the proper modality that fit with players need and enable them to develop their planning and moves skills to highest level. The training process relies on many modalities aim to improve the control elements in the professional sport, and these modalities submitted to a specific system that determine the size and training intensively, breaking periods and working system. The training modalities term means all the used modalities at the training unit, that adopt a specific type and form of training. This type of training aims to achieve a specific goal. John Troob (1988,28123) and Mohammed Othman (1990,29-129) indicated that the training modality is considered as a specific planning represent the selection and organizing the training content and form based on the goal of the subject.

The coach is confronting difficulties in selecting the training that will achieve his target, and all training modalities have different goals. Each modality achieves specific goals. So, the coach has to select the training modality to achieve the desired objective. The variety of training modalities will increase the players excitement unlike if the training is limit on two or three training modalities. The training modalities are considered executive means at the training unit to develop the training process to the individual and it's a behaviour achieve the require objective through organized sport training practices.

\section{MATERIALS AND METHODS}

\section{Procedures}

There are many of training modalities that achieve a specific duty, and we have to select the proper modality to achieve the purpose. Basing on that, the training means and styles to raise the sport level were varied. The coach has to know these variables and modalities and the capability to use them in the right way and fit with training trends.

The training modality is considered as a procedure done cording to a plan and to achieve the required objective. Regarding to all that, training is a planned procedure to achieve public or private training goals by identifying the three achievement elements (Physical, Technical and planning elements). The training modalities for each element can be determined from teaching methods prospects. The training can be identified as the organized arrangement to the training content considering laws and the scientific principles to the training process specially loading values and training means.

\section{Assessing the learning process to the stages of $(10: 53,52)$}

This is the universal concept to the training modality term. This can be applied on three achievement elements. Allawi (1992) mentioned that aimed at of training modalities is the different means that can develop the training status and sport formula to a maximum point through the organized training to the athletic. $\mathrm{He}$ divided the modalities to:

- - Training modalities of Physical Characteristics.

- -Training Modalities of Moves skills.

- - Training modalities of Planning preparation.

- - Training modalities of Physical preparation.

These different modalities are the components of one procedure which is the Athletic training procedure, and the necessity to concern all to reach a high level in sport (34:21.211). Wajdi Al-Fatih and Mohammed Lutfi (2002) defined the athletic training as the different means that could develop and raise the training status to 
a maximum degree of the athletic (45:371). Also, Ahmed Bastawsi (1999) highlighted on the basic training modalities to develop the muscle mass and speed, and they are represented in the hereunder:

- Continuous load training.

- - Interval training.

- $\quad$ Repetition training.

In addition to all above basic modalities, there are related specific means and plans called by some other references as training modalities too such as: circuit training with all its branches, plyometric training and Pyramid training (12:273).

\section{Conditioning that should be considered during training modality selection}

- The direct of achievement of purpose of the training unit that should be clear.

- Fit with the individual training status.

- Fit with the coach's skills and his capability to apply the modality.

- Training modalities put based on the practiced athletic activity characteristics and requirements.

- Helping to use the motivated energy that urge the player to keep moving athletic exercise.

\section{Measures}

1-Interval training (high intensity- Extensive intensity), Plyometric training, Weight training, ISO Kinetic training, Hypoxic training, Circuit training, station training, Alternatives training, Pendulum training, Fartlek training modality (playing speedily), Intermittent exercise, Compressor training, Muscle contraction process, Isotonique training, Ballistic training, -Intensive training and Training various.

In this paper we will display the next training modality due regarding it one of the best favoured training modalities in karate:

- Interval training (high intensity- Extensive intensity)

- Plyometric training.

- Weight training.

- Iso kinetic training.

\section{Analysis}

The researcher used the statistical bag (SPSS) to find the appropriate statistical treatments for the study.

Interval training (High intensive-low intensive)

Interval training is considered one of the main modalities that had used in the second half of twenty century with positive result not only in athletic activities such as swimming, track and field and bicycles, and also for all other games and fighting games. This kind of training concerns to develop and improve the specific physical capabilities, which the interval training is an important and basic factor generally in level progress. So, the interval training can be identified as one of the basic modalities to improve the physical capabilities level relying on the adaption achievement between exercising and rest periods. The interval training relies in general on the following elements:

- $\quad$-High intensity of training, Intensity size of training, Rest periods.

Second: Player's level determined by the hereunder:

- -Biological player's age, Years of training, Private physical capabilities level and Skill level.

Psychological and social status of the player

- $\quad$-Married or single, Student or labour and Psychological state. 
Instead the ability of developing the physical capabilities, muscles mass, speed and load in its different modalities and styles, but their development will be in better way when some of the body organs such as respiratory system in addition to the metabolic operations at the muscle to correct training, repetition and intensive stimulus which represented in the interval training ,that is considered the best and active modality to develop the myodynamic, speed and load. So, the interval training term is basically related to the coolingoff periods between exercises and the repletion of this work. Kool, Reindel and others (1995) had seen that interval training in the side of Physiology is not related to the exercise repetition and cooling-off periods only, but also through the rated and suitable rates for each of repetition and interval periods, which is stimulated by intensity that we will discuss it through the two interval periods modalities as below:

- $\quad$-High intensity interval training and Extensive intensity interval training.

\section{High intensity interval training}

This kind of training aims to develop the below private physical capabilities:

- $\quad$-Maximum speed endurance and Maximum power endurance.

- $\quad$-Distinguished force in speed and explosive power.

According to the mentioned above, the high intensity interval training can be described through the following of load components:

- $\quad$-Training stimulus intensity. It is the difficulty mount in doing the exercise and it is divided into:

- -Maximum between 90-100\%.

- -High between $75-90 \%$.

- $\quad$-Middle between 50-75\%.

Stimulus intensity of training load can be determined by the specific training of sprint, swimming, bicycle and karate, in addition to develop the muscle power in case of using additional loads than body weight or without that, and the stimulus intensity should be high as follows:

- $\quad$-Speed and endurance training is $80-90 \%$ of maximum intensity.

- $\quad$-Muscle force is $75 \%$ of maximum intensity.

The stimulus training size is related to the size of training which is represented in the specific repeated exercises for each training unit with stimulus intensity directly. According to the increase of stimulus training at the high intensity interval training will increase the repeated trainings exercises to avoid reaching the player to the high intensity and maximum fatigue, and it should by gradually to control the relationship between repeating exercise size, intensity and recommended cooling-off period (8:82) (7:536).

- - Cooling-off period. This period will be too long for the high intensity interval training than extensive intensity interval training due to the training stimulus intensity increase, and this will determine the intervals resting that we talked about in advance. The cooling-off period will be determined as below:

- $\quad$-Advanced players 90-180, when the pulse is 110-120 for minute.

- -Junior players 90-180, when the pulse is 110-120 for minute.

- -Duration of stimulus must be no more than $80-90 \%$ for each exercise of the maximum level endure by the player for the sprint and swimming sport. While the specific exercises for the muscle force must be no more than $75 \%$ of the player maximum capability $(8: 82)(7: 536)$.

Physiological features of high intensity Interval Training

high intensity Interval Training aims basically to develop the specific load such as maximum power endurance and maximum speed endurance specially at the short and middle periods. In addition to that, developing the 
distinguished power by speed and explosive power. During the process of high intensity Interval Training the body will be exposed to oxygen debt training to 10-12 litter, while the maximum hypoxic training will be from 18-20 litter. Whenever the effort increased the oxygen debt increased, so the muscles performance will be anaerobic with hypoxic oxygen. This process will make the blood responsible to equalize the metabolic waste acid and their balance. So, the oxygen debt will get better during high intensity interval training 4-5 $\mathrm{m}$ and breaks between exercises.

The blood equation capacity is very important to equalize the metabolic waste acid like its responsibility to get rid of $\mathrm{CO}_{2}$, Lactic Acid and other metabolic waste Acids resulted from other general muscles or through the strong signals of high intensity Interval Training fatigue. The body will adapt with this condition by increasing the capability that equalize balance in the blood, and some hormones that are related with the signals of new load through Peripheral nervous system under-effect of parasympathetic nervous system during recovery. Part of lactic Acid will be transferred to $\mathrm{CO}_{2}$ and be removed through blood and lungs to an air. The athletic who trains well can feel adaption of load than before.

The Peripheral nervous system is similar in the high intensity Interval Training the adaption as in the extensive intensity Interval Training, and the effort doesn't effect on intensity which high intensity Interval Training adaption characterized with at the extensive intensity Interval Training, and the high intensity effort is not affective which high intensity Interval Training is characterized within the limits of $\% 25$ of the player's ability during the oxygen consumption only, but even on the cross section of the muscle. When the muscle exposed to fatigue with organizing and stimulus repetitions plus recommended break that fit with that intensity.

\section{RESULTS}

Comparison table between the basic training modalities (30:33).

Table 1. Unit training sample by using Interval high intensity interval training.

\begin{tabular}{|c|c|c|c|}
\hline \multirow[t]{2}{*}{ Modality Features } & \multirow[t]{2}{*}{ Repetition } & \multicolumn{2}{|l|}{ Interval } \\
\hline & & High intensity & Extensive intensity \\
\hline Intensity & $\begin{array}{l}\text {-High Intensity } \\
90: \% 100\end{array}$ & $\begin{array}{l}\text {-Intensive } \\
80: \% 90\end{array}$ & \\
\hline Size & $\begin{array}{l}\text {-Extensive } \\
3: 5 \text { groups of exercises }\end{array}$ & $\begin{array}{l}\text {-Medium } \\
3: 5 \text { groups of exercises } \\
5: 10 \text { repetition for each } \\
\text { group }\end{array}$ & $\begin{array}{l}\text {-Medium of extensive } \\
\text { 60: } \% 89\end{array}$ \\
\hline $\begin{array}{l}\text { Comfortable } \\
\text { environment }\end{array}$ & $\begin{array}{l}- \text { Complete } \\
6 \text { to } 3 \text { minuets }\end{array}$ & $\begin{array}{l}\text {-In-complete/big } \\
1: 3,5 \text { minutes }\end{array}$ & $\begin{array}{l}\text { Big } \\
\text { 3:5 groups of exercises } \\
\text { 10:20 repetition to the group } \\
\end{array}$ \\
\hline \multirow[t]{2}{*}{ Training influence } & -Maximum power & Maximum power & $\begin{array}{l}\text {-In-complete, small } \\
\text { General endurance }\end{array}$ \\
\hline & $\begin{array}{l}\text {-Maximum power } \\
\text {-Explosive power. } \\
\text {-Speed endurance and } \\
\text { maximum power }\end{array}$ & $\begin{array}{l}\text { Maximum power } \\
\text {-Explosive power. } \\
\text {-Speed endurance and } \\
\text { maximum power }\end{array}$ & $\begin{array}{l}\text {-Power endurance } \\
\text {-Speed endurance. }\end{array}$ \\
\hline $\begin{array}{l}\text { Physiological } \\
\text { influence }\end{array}$ & $\begin{array}{l}\text {-Increasing the muscle size. } \\
\text {-Saving power. } \\
\text {-Metabolic anaerobic }\end{array}$ & $\begin{array}{l}\text {-Increasing the heart size. } \\
\text {-Saving power. } \\
\text {-Metabolic anaerobic }\end{array}$ & $\begin{array}{l}\text {-Control of respiratory system. } \\
\text {-Efficiency in taking Oxygen. } \\
\text {-Metabolic anaerobic }\end{array}$ \\
\hline
\end{tabular}




\begin{tabular}{|l|l|l|l|}
\hline Proper activities & $\begin{array}{l}\text {-Competition time not more than } \\
30 \text { seconds. } \\
\text {-Weight lifting 100, sprint is 100 } \\
\text { m, swimming. }\end{array}$ & $\begin{array}{l}\text {-Competition no more } 8 \\
\text { minutes. } \\
\text {-Fighting such as Karate, } \\
\text { Judo and Taekwondo } 800 \\
\text { m. } \\
\text {-Running is 2000 m, metition is no more } 8 \\
\text { swimming variety of types }\end{array}$ & $\begin{array}{l}\text {-Comutes, group games, racket } \\
\text { games }\end{array}$ \\
\hline
\end{tabular}

Table 2. Planning target. Attack a movable competitor.

\begin{tabular}{|c|c|c|c|c|c|c|c|c|}
\hline \multirow{3}{*}{\multicolumn{2}{|c|}{ Unit's parts }} & \multirow[t]{3}{*}{$\begin{array}{l}\text { Total } \\
\text { time }\end{array}$} & \multirow[t]{3}{*}{$\begin{array}{l}\text { Training } \\
\text { No. }\end{array}$} & \multirow{2}{*}{\multicolumn{5}{|c|}{$\begin{array}{l}\text { Training load } \\
\text { Value }\end{array}$}} \\
\hline & & & & & & & & \\
\hline & & & & $\begin{array}{l}\text { Performance } \\
\text { time }\end{array}$ & Repetition & $\begin{array}{l}\text { Cooling-off } \\
\text { between } \\
\text { repetitions }\end{array}$ & $\begin{array}{l}\text { Number } \\
\text { of } \\
\text { groups }\end{array}$ & $\begin{array}{l}\text { Cooling- } \\
\text { off } \\
\text { between } \\
\text { groups }\end{array}$ \\
\hline \multicolumn{2}{|l|}{ Warming } & 6 & $1-2-3-4-5$ & $1 \mathrm{~m}$ & 1 & $12 \mathrm{~s}$ & 1 & 0 \\
\hline \multicolumn{2}{|c|}{ Physical preparation } & 56 & $\begin{array}{l}\text { 6-7-8-9- } \\
10\end{array}$ & $10 \mathrm{~m}$ & 3 & $20 \mathrm{~s}$ & 4 & $45 s$ \\
\hline \multirow[t]{2}{*}{$\begin{array}{l}\text { Skill } \\
\text { preparation }\end{array}$} & Individual & 18 & $\begin{array}{l}11-12- \\
13-14-15\end{array}$ & $10 \mathrm{~m}$ & 3 & $20 \mathrm{~s}$ & 4 & $45 \mathrm{~s}$ \\
\hline & Compound & 10 & $16-17$ & $20 \mathrm{~s}$ & 3 & $20 \mathrm{~s}$ & 3 & $40 \mathrm{~s}$ \\
\hline \multicolumn{2}{|c|}{ Planning preparation } & 5 & 18-19 & $10 \mathrm{~s}$ & 3 & $15 \mathrm{~s}$ & 3 & $25 \mathrm{~s}$ \\
\hline \multicolumn{2}{|l|}{ Final part } & 6 & $\begin{array}{l}20-21- \\
22-23- \\
24-25- \\
26-27\end{array}$ & $1 \mathrm{~m}$ & 1 & $12 \mathrm{~s}$ & 1 & 0 \\
\hline
\end{tabular}

Table 3. Warming exercises.

\begin{tabular}{|l|l|}
\hline $1-$ & (standing) walking forward with wide steps and moving hands forward and backward. Distinguished speed. \\
\hline $2-$ & (standing) light running round Karate stadium. \\
\hline $3-$ & (standing) varied running round the stadium. \\
\hline $4-$ & (standing) running with rising hands up suddenly, then put them down. \\
\hline $5-$ & (standing) running forward and rise both knees up. \\
\hline
\end{tabular}

Table 4. Specific preparation physical training.

\begin{tabular}{|c|l|}
\hline $1-$ & Standing opposite the Swedish bench. Jumping over the bench (Kiza Mimaoshi Jerri). \\
\hline 2- & (Jeo Komitia Hadatshi). Heading forward and backward. Speed endurance. \\
\hline 3- & (Jeo Komitia Hadatshi). Fixing the rubber with both arms (Kiza Mizoki performance). Speed exercise. \\
\hline 4- & Standing opposite to the wall and touching it. Moving legs up and backward. Flexibility. \\
\hline
\end{tabular}


Table 5. Skill preparation exercises.

\begin{tabular}{|l|l|}
\hline $1-$ & $\begin{array}{l}\text { Jeo Komitia Hadatshi. Successive individual skills with legs against negative competitor. Kiza Mizoki- } \\
\text { Jiakozoki-Ourakin. }\end{array}$ \\
\hline 2- & $\begin{array}{l}\text { Jeo Komitia Hadatshi. Successive compound skills with legs against negative competitor. Kiza-Mawashi- } \\
\text { Jebbri-Mawshi Jebbri. }\end{array}$ \\
\hline 3- & $\begin{array}{l}\text { Jeo Komitia Hadatshi. Successive individual compound with arms against negative competitor. Kiza Mizoki- } \\
\text { Jiakozoki. }\end{array}$ \\
\hline 4- & $\begin{array}{l}\text { Jeo Komitia Hadatshi. Successive compound skills with legs against negative competitor. Kiza-Mawashi- } \\
\text { Jebbri-Mawshi Jebbri. }\end{array}$ \\
\hline
\end{tabular}

Table 6. Planning exercise.

\begin{tabular}{|l|l|}
\hline $1-$ & Jeo Komitia Hadatshi. Face to face to do an offensive adverse determined by the coach to one of the players. \\
\hline $2-$ & $\begin{array}{l}\text { Jeo Komitia Hadatshi. Face to face to do an offensive and defensive restricted game determined by the } \\
\text { coach in specific time to exchange to both players. }\end{array}$ \\
\hline $3-$ & $\begin{array}{l}\text { Jeo Komitia Hadatshi. Face to face to do fast an offensive and defensive restricted game determined by the } \\
\text { coach in specific time to exchange to both players. }\end{array}$ \\
\hline
\end{tabular}

Table 7. Slowing exercises.

\begin{tabular}{|l|l|}
\hline $1-$ & $\begin{array}{l}\text { (Standing). Walking slow with circling arms backward slowly, and take deep inhalation followed by exhalation } \\
\text { when the arms became near the body. }\end{array}$ \\
\hline $2-$ & (Standing) slow running forward and backward with short steps. \\
\hline $3-$ & Laying with bending knees and shake the legs muscles. \\
\hline $4-$ & Standing with opening legs with arms pendulum move. \\
\hline $5-$ & $\begin{array}{l}\text { Standing with opening legs, and the trunk is sloping forward, and arms are forward and backward with } \\
\text { exchanged move. }\end{array}$ \\
\hline
\end{tabular}

\section{Plyometric guidelines}

There are some instructions should be considered during Plyometric training:

1. Warming and Cooling-off.

Regarding the Plyometric training need flexibility and fitness, warming exercises should be made before plyometric training followed by all kinds of rolling and running movements.

2. Proper high intensity.

Thigh intensity of plyometric training will achieve a better training, and the best response is when the muscle grown quickly. When the exercises shall be in high intensity, the player has to take sufficient breaks to do exercises.

3. Graded load increase.

The training programs has resisted the extra weights and enforce the extra weight the muscles to work in high intensity. This situation can be under-control by the player by controlling the highs that player jump's on.

4. Exaggerate powder and shorting time.

Both power and acceleration in Plyometric training are very important in all critical and important statuses, and it required speed to extract power in less time by pushing move. The quickest in this move is the great to generate and achieve longest distance as shoot putting. 
5. The optimal number of repetitions.

The repetition limits from 8-10 with small number to release the follow up and sequence, and more repetition in the exercise including less than that, and the groups number should be changeable and fit with it.

6. The proper breaking.

The proper break is 1-2 minutes between repetitions. Sometimes is enough for the fatigue nervous system from the Plyometric training. The rest between the Plyometric training days are important for muscles and cartilages recovery, which is 2-3 per-week to get better results.

7. Create the proper foundation.

Weight training programs must be designed for completion, and not for extension and validity to develop the explosive power. The capability foundation doesn't need to Plyometric training performance. Both Yuri Veroshanski and Khornovove said the maximum body bending twice before starting the deep sprint and regular Plyometric training.

8. Individuality in training.

In order to get better results, we will discuss the Plyometric training individually in order to understand the capability of each athletic and the proper training quantity. Some of the research aimed to measure the student's capability and determine the optimal training quantity. In most of sport training of the body, they are relying on the Art of training than as science (22:41).

\section{What are the concerns during Plyometric training performance?}

- The number of repetitions must be 6-10 times for each group.

- The beginners perform two to three groups, the advanced 3-5 groups and high-level athletes 6-10 groups.

- The cooling-off between groups is 2 minutes.

- These exercises should be performed after intensive warming (19:30).

\section{Polymetric training characteristics}

- Improve correspondence inside muscle, then it will lead to quick earnings in powers level without increase in the body weight.

- It has a great role in activities that explosive power plays an important role such as long sprint.

- It forms a training substance to the players with speed force and high training level, that force progress level is hard reach to them.

- The division of such exercises (small, medium and high intensity) can be used in different age and level, while they fit with the activity.

\section{Plyometric training deficits}

- It requires a prior physical training and muscular exercises.

- $\quad$ This kind of training achieves no excellence success without doing it correctly (22:42).

\section{Plyometric training types}

Plyometric training has many numbers of exercises, but it should be graded from simple exercises to the complicated one. Ondrej Duda (1988) referred that the scientist Donaldo Show divided these exercises into two parts:

1-Lower Body part.

2-Upper Body part. 
He divided the lower body part exercises into six types:

\section{Weight training}

Since 40 years ago, the common concept of weight training affect the players moves and affect the muscle length negatively and enforce the player to perform the required moves incorrectly, un-accurate and unbalanced. This concept was changed since 30 years ago, and weight training became the optimal modality to develop the muscle power element especially the maximum power. Weight training contributed in many varied exercises and Athletics with no exception to develop the maximum power but in different levels relying on the power types importance for each game.

This kind of training was founded in the United States of America to develop power to the players, and also it is considered a very important for giving a training plan and the player are high weights for short period, and by that muscle power will be grown up. Mostly, this kind of training is related to the physical training by doing physical exercises with little weights caught by hands or fasten to the legs, or by wearing shirt full of weights or sand. This kind of training is useful to strong the legs muscles, arm muscles and the hip muscles, and also enable the players to defeat their competitors and improve his movements. Weight training is known of using weights to develop the muscles power relying on increasing load concept. Weight training has to last for a proper period to be beneficial to the players, if the training was interrupted its benefit will be lost. The continuous weight training will give players the influenced fatigue (43:339-340).

Talha Husam Aldean (1994) mentioned that weight training includes all different kinds of resistant changeable training, and free weights or weights devices can be applied. The scientific studies still on trying to reduce using it in all different activities (4:45).

Abdulaziz Alnumer and Nareeman Al-Khateeb (2000) referred to the weight training as a preparation modality for the player by using a resistant grading to increase the ability to produce power and confront it (22:37) $(17: 14)$.

\section{Weight training principles}

The weight training principle as Mohammed Mahmood Abduldayem mentioned (1993) are: Adapting the principle of exercise intensity. -Recovery principle, Resistant Maximum level principal, Move speed control principle, Full range of move principle, Muscle balance principle and Training privacy principle (40:24).

In addition to all mentioned above, Adil Ramadhan Hashim (1997) added four other important principles: Privacy principle, Extra load principle, Grading principle and adaption principle.

\section{New technology invention in Karate}

Intelligent devices have entered many applications in sport field, by issuing different sport activities applications such as karate to support learning process and self-training on skills performance. In addition, you all that, develop the physical side or evaluate the skills performance and finding out performance mistakes. These devices are easy to connect them on big screens to explain and watch their contents even activate with the show inside the training and teaching halls. The world Karate federation updated some applications in this training, refereeing and competition fields, and get benefit from new technology inventions. 


\section{Devices used in Karate training}

Kinesis class training

It consisted of four phases that can perform a great number of loads, power and flexibility exercises. It started from 30 minutes. These training stand for resistant with free movement in all directions using arms and legs skills in Karate.

\section{Reaction ball}

It is and accelerating device for reactions and developing the skills, individual and compound skills, that enable the karate players for quick responding to change distances and corners. It is very hard modality to improve the precise and timing of the punch.

Kick target

It is used for speed and precise training. It is characterized with different highs to the kicks and punches.

\section{Multi-Jump trainer}

It is multi-stands device. The athlete can do many jumps in different directions.

Iso Kinetic training modality (similar to motion)

The Iso Kinetic contraction was defined Abu Al-Ulah Ahmed Abdul-Fatah (2003) as the maximum muscle contraction that done in fixed speed through the completed range of the motion. The word "Iso" means the similar or equal, and the word "Kinetic" means the move. From what mentioned above, the name of the muscle contraction came as a result of moves similarity that lead to the athletic activity. The theoretical and practical prospective of training is to develop the muscle's power by using the muscle contraction that is similar to motion. Iso Kinetic is considered the proper modality to the performance nature during the Athletic activity (209:2).

\section{DISCUSSION}

Regarding the research requirements, and to improve the comparison levels between the modality features, the tables were completed based on the given data.

*Load intensity* \%90, unit time is120.

- Physical Target-Moves responding speed-power with speed and flexibility.

- Skill target.

The soviet scientists invented this style to develop the muscle capability which came under the name of Polymeric training. Yuri Veroshanski was the first one who used this kind of training and became common after the successful win for the Russian sprinter Valeri Bovogov, and he got the golden medal in $100 \mathrm{~m}$ race in 10 seconds at Munich 1970.

Plyometric is Russian word consisted of two syllables, the first one means the bigger, width and the longest, and the second one means measurement, evaluation and comparison. The word plyometric showed up for the first time at the Russian references in 1966, and Russian were the first who used this kind of training. Plymetric training was used mostly in jump, shooting and sprint in Athletics. The Russian great progress in the late years in these competitions due to the use of Plyometric training and also in all other games in Soviet Federation. 
The Plyometric training became common as a resistant training in the east for more than 25 years. The international coach Valeri Bovogov used the Plyometric training during 1960s with some spring game players and made a great success. Then, he returned using the same modality in 1972 in Munich Olympic games, when the soviet sprinter Valeri Bovogov the gold medal in $100 \mathrm{~m}$ race (sprint), then he won the gold medal in $200 \mathrm{~m}$ race (sprint). The main reason of wining in both races is following the Plyometric training.

\section{Plyometric training essence and importance}

Plyometric training is considered one of the terms used widely in math, that requires utilizing power and speed power. This kind of training is used to develop muscle capability and the explosive power. Also, it is used to improve the relationship between the maximum power and the explosive power (22:28).

\section{Plyometric training concept}

The traditional Plyometric training relies on the acceleration and braking due to the body weight in its dynamic movements like in all kinds of sprint regression. The goal of this modality is to develop the muscle capability and will improve the dynamic performance during sprint. Plyometric training is directing power in its correct roots to raise the speed performance level (18:79-85). Abdul-Aziz Alnamer remind Nariman Al-Khateeb that the word Plyometric is used to describe a type of exercises characterized with muscle contractions of highly level of changed muscle capability due to the quick extension of the working muscle $(2: 38)$.

\section{Plyometric training performance}

The plyometric training idea or train the muscle explosive capability on confronting the muscle for outside resistant such as weight or body weight against gravity after the longest muscle expansion. The muscle works to be extended then followed with central quick contraction. This kind of contraction can be on three stages. The contraction starts with muscle long contraction (non-central) increased gradually till be equal with the resistant, and then transferred to a muscle short contraction (central). This kind of training will allow many efficiencies on many joints, and this will help the player to do Plyometric training for example: all kinds of sprint, fall, skiing from high areas followed by sprint directly due to the muscle length increase before making the required contraction of the movement will result a minimum possible power in less time (41:15).

\section{CONCLUSION}

The main results obtained by the researcher is Discussing in details the modern training methods of karate by studying the coach's levels. In addition, Explaining the modern application used in karate. Finally reaching to the basic points of players exercises, specially at the stage of increasing the muscle mass.

\section{REFERENCES}

Abdul-Fatah, A. (1997). Sport training, Physiological basics: Al-Fikr Al-Arabi press house-Cairo. Abdul-Fatah, A. (2003). Sport and training Physiology: Al-Fikr Al-Arabi press house-Cairo.

Al-Namir, A. \& Alkhateeb, N. (1999). Sport training, weight training and power programs design and training season planning: Alkitab center for publishing, Cairo.

Alsayed, A. (1992). Athletic training theory, training and Physiology of endurance: Al-Shiyaa Alharb press house. Cairo.

Alsayed, A. (1997). Athletic training theories, power training and Physiology: Alkutab center for publishing, Cairo. 
Aqeel, H. (2009). The influence of high intensity interval training and Hypoxic to develop some physical, basic skills, Biochemistry and functional variables to Junior Football players: PhD. Thesis, Basra University, College of Physical Education.

Al-Ashqar, H. (1982). Interval training application on the morphologic and records for sub-juniors in sprint and walking race: $\mathrm{A}$ presented paper as one of the $\mathrm{PhD}$. degree requirements at philosophy in Physical and Sport Education at Alexandria college of physical Education, Hilwan University.

Al-Shahat, I.\& Mustafa, A. (2004). Hypoxic training influence on some physiological variables, and skill performance for Judo players: A presented paper as one of the Master Degree requirements in Physical and sport Education at the college of Physical Education/Tanta University.

Al-Hinawi, S. (2004). Weight training program influence on the technical performance level for some moves on the balance device for Gymnastics player under 10 years: A presented paper as one of the Master Degree requirements in Physical Education at the college of Physical Education/Minia University.

Bataweesi, A. (1999). Athletic basis and theories: Al-Fekr Alarabi press house, Cairo.

Darweeish, T. (1998). Plyometric training: Al-Fekr Alarabi press house, Cairo.

Hilmi, I. (1980). Swimming training between theory and Application: Al-Maref pres house, Cairo.

Hilmi, I. (1977). Modern Trends in Swimming Training: Al-Maref pres house, Cairo.

Husam Aldean, T. (1997). Load Athletic training Encyclopedia Biologically and Biomechanically: Alkitab center for publishing, Cairo.

Husam Aldean, T. (1994). Motion and function foundation of sport training: Al-Fikr Alarabi press house, Cairo.

Husam Aldean, T. \& Hamad, M., etal. (1997). Training scientific Encyclopedia: Alkitab center for publishing, Cairo.

Khalefah, A.\& Mohammed, H. (2003). Using circuit training effectiveness on performance level for some offensive defensive skills in basketball: A presented paper as one of the Master Degree requirements in Physical and sport Education at the college of Physical Education/Al-Minia University.

Mahmood, A. \& Ibrahim, M. (2005). Athletic training limits Encyclopedia in Karate: Al-Maeref Al-Exndria Intitute.

Mahmood, A. \& Ibrahim, M. (2011). Modern limits and trends for rated and planning style of karate training: Al-Maeref Al-Exandria Intitute.

Mahmood, A. \& Ibrahim, M. (2011). Modern Trends and limits of rated styles and planning for training program in Karate: Al-Maeref Alexandria Intitute.

Mahroos, E. (2004). The influence of divergent training by using weights and plyometric on some of special physical capabilities and player's record for the long Jumping: A presented paper as one of the PhD. Philosophy requirements Physical Education, college of Education.

Mukhtar, H. Football Technical manager: Alkitab center for publishing. Cairo.

Mukhtar, H. (1988). Basis of planning Athletic training programs: Zahran press house, Cairo.

Nabeel, A. \& Abdul-Muneam M. (2004). Intensive training effectiveness on some physiologic variabrs and records level for the short distance swimmers: Master Thesis. College of Physical EducationMinia.

Radwan, Ahmed. (2004). The influence of suggested program of weight training on some physical variables, and improve the swimmer's records of Sub-Juniors under 13 years: A presented paper as one of the Master Degree requirements in Physical and sport Education at the college of Physical Education/Al-Minia University.

Sarawi, A.\& Ahmed, M. (2002). Weight training program influence on a group of back moves and some physiological variables: A presented paper as one of the Master Degree requirements in Physical and sport Education at the college of Physical Education/Al-Mansoorah University. 
Thaki, A.\& Raeb, O. Scientific foundations of Swimming training: Al-Fekr Alarabi press house. Thaki, A.\& Tariq, N. Scientific foundations of Swimming training: Al-Fekr Alarabi press.

\section{(c)}

This work is licensed under a Attribution-NonCommercial-NoDerivatives 4.0 International (CC BY-NC-ND 4.0). 